\title{
Dear Mrs. P
}

Cite as: CMAJ 2019 February 11;191:E168-9. doi: 10.1503/cmaj.181235

CMAJ Podcasts: audio reading at https://soundcloud.com/cmajpodcasts/181235-enc

ear Mrs. P,

Your disease was not a kind one. You told me that it started as a mild weakness in your left foot, just more than a year ago. Several months later, you found that managing house chores, keeping up with your friends, and caring for your husband was becoming increasingly difficult. Fast-forward a few more weeks and you were admitted to the geriatrics unit for rehabilitation. The weakness was creeping up your body. By the time I met you, the disease had claimed your ability to walk and stand on your own. You depended on other people to get out of bed, to get dressed and to wash yourself. The disease would permanently keep you from your home of 50 years, and your husband of more than 60 . You knew all this, though, so let me write to you about some things that you might not have known, instead.

Did I ever tell you that I had no idea how to approach you at first? You see, the bulk of my clinical encounters were in the realm of curative medicine, but you fell outside of that. You knew your disease was not reversible and, in fact, was expected to get worse. Your care plan clearly had a more palliative flavour. I had some experience caring for acutely dying patients, but that was not exactly you, either. You were still participating in physiotherapy, eating 3 meals a day - with the occasional baked treat from your visitors - and going on day passes to see your husband. Moreover, you were not "officially palliative" yet. So where did that leave you?

I had to go back to the basics. No daily laboratory work or fancy imaging to hide behind. No treatment algorithms to rely on. Just me, you and your symptoms. Patient-centred care was not very difficult when it was really the only way palliative care could be done. Every day we revisited how you were feeling, physically and mentally, and we tackled each problem one by one. Together, we decided that physiotherapy was to keep your muscles from getting too stiff, not to get you home. We agreed on a soft diet to prevent the episodes of choking that were so anxiety-provoking for you, but no one
Of course, your disease did not slow down just for me to figure this out. No, it stayed true to its natural course. You began to require a mechanical lift for transfers. Your gaze continued to lower as the weight of your head overwhelmed the strength of your neck. You used to say, "All I can see is everyone's shoes!", but the jokes came less frequently as your energy levels declined. You spent one night in an

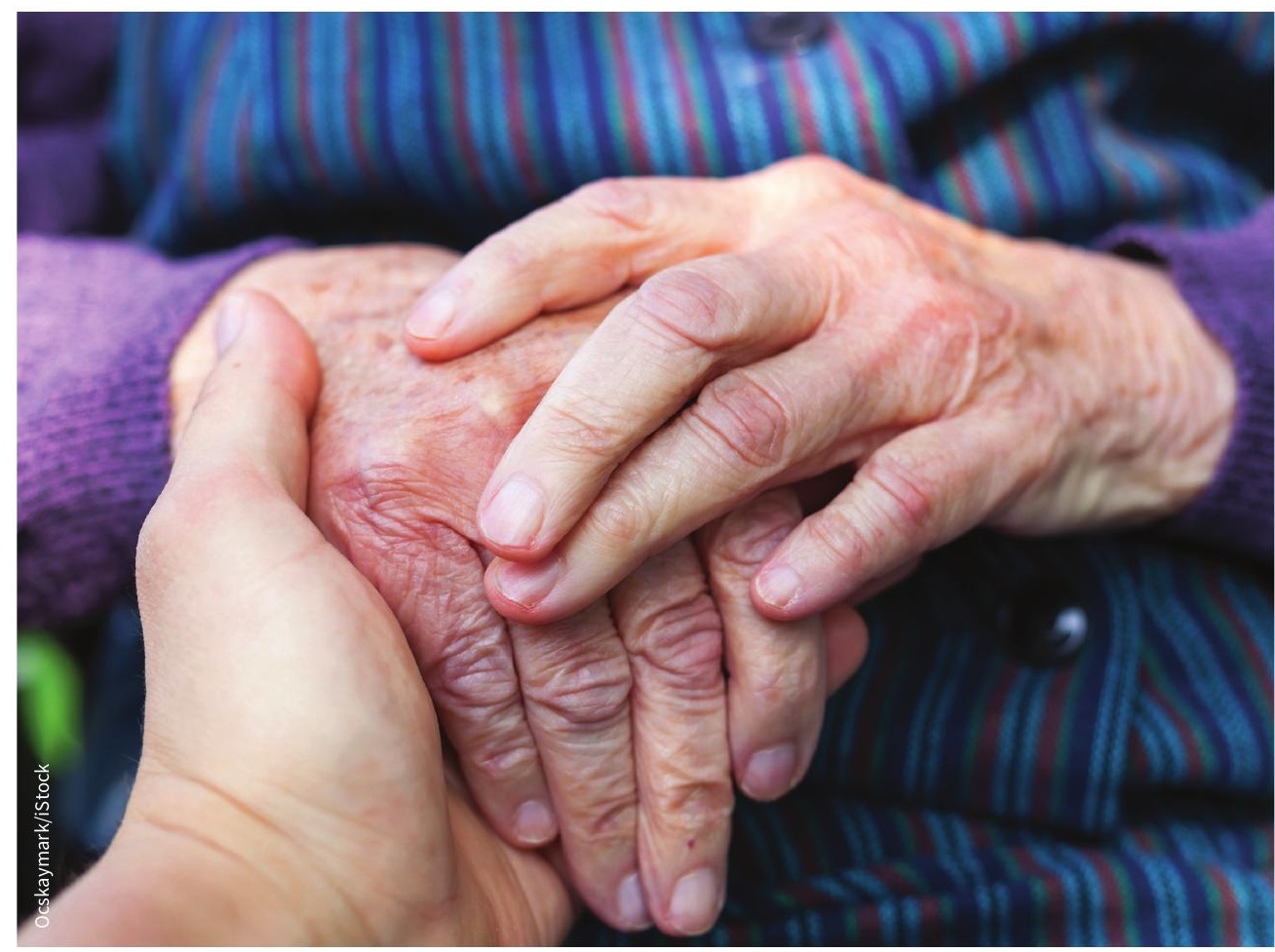

minded if you snuck in a cookie or 2 . We treated curable infections because the feeling of being sick would be uncomfortable. Comfort was our priority. Even though you did not own the label of "palliative patient," we did not need one to provide that sort of care. You showed me that palliative care is a spectrum, not a state. uncomfortable position that you were too weak to get out of and a cascade of any and all pain that ever ran through you came chasing after. The pain would cause you to spend many more nights quietly crying. When your husband died at the height of this pain, I cried with you. You asked, still as pleasant a woman as ever, "How much longer will this agony last?" 
A loaded question with no definitive answer. Through your experience of illness, I learned that palliative care is about dealing with uncertainty rather than making promises and about accepting some losses rather than aiming for perfection. We cherished the restful nights that we managed to achieve and kept working on the others that fell short. There was also some pain, like that of losing a life partner, that we knew no medicine could touch. In those cases, empathy and compassion were the only treatments available.

We left things in a better state than that, though, would you not say? My clerkship rotation came to an end only after we had found a sweet spot for your pain control. You were also beginning to find peace with your husband's death. When I came into your room to say goodbye for the final time, you were sitting in your wheelchair by the window, facing the glimmering lake beyond the field. Your room was filled with blooming flowers from your husband's funeral. We chatted about your mood, your symptoms, and the signs of spring outside. I got to hear one last story about your younger years before I had to leave. As I stood up, with my hand on your shoulder, you looked at me with a sweet smile on your face and said, "It was nice knowing you." The finality of that statement paralyzed me for a few moments before I blurted out a short "thank you," and left. What I meant to say was thank you for sharing your kindness, even when life was not kind to you, and for teaching me how to care for patients without being able to completely fix them.

Yours truly,

Zoe

\section{Siu Yu Zoe Lau BSc(Hon)}

Queen's University School of Medicine, Kingston, Ont.

This article has been peer reviewed.

This is a true story. The patient has given her consent for this story to be told.

Editor's note: This article was the 2018 winner of the Undergraduate Narrative Award for Palliative Medicine, hosted by the Canadian Society of Palliative Care Physicians. 